\title{
Управление проектной командной работой как социальным технопакетом
}

\author{
${ }^{1}$ Федотова М.А., ${ }^{2}$ Полушин П.В. \\ ${ }^{1}$ Московский авиационный институт (национальный исследовательский университет), \\ Россия, г. Москва, 125993, Волоколамское шоссе, 4 \\ ${ }^{2}$ Академия Государственной противопожарной службы МЧС России \\ Россия, г. Москва, 129366, ул. Бориса Галушкина, 4 \\ E-mail: fedotova-ma@yandex.ru, petr-poluchin@rambler.ru
}

\begin{abstract}
Аннотация. Предложена авторская интерпретация развития теории социальных технологий на базе концепции соционавигации в виде технопакетного подхода к системному управлению проектной командной работой, основанная на представлении этой деятельности как процесса в технологической сети («технопакета» - ТП). Определены актуальные проблемы системного управления проектной командной работой, решение которых необходимо для повышения эффективности управленческой практики. Введены дополнительные понятия: «развивающая» технология, представляющая собой технологию развития, ключевой, «замыкающей» технологии ТП, которая позволяет совершенствовать ТП, адаптируя его к социальным и техникотехнологическим изменениям; «оптимизирующая» технология - позволяющая оптимизировать параметры используемых «базовой» и «продуктовых» технологий. Предложена концепция интегральной системы моделей информационного субпакета технопакета «системное управление проектной командной работой», основанная на «мягких» вычислениях (МАИ/МАС - технологиях Т. Саати).
\end{abstract}

Ключевые слова: социальные технологии, соционавигация, технопакет, МАИ/МАС - технологии Т. Саати, интегральная система моделей, информационный субпакет.

Для цитирования: Федотова М.А., Полушин П.В. 2020. Управление проектной командной работой как социальным технопакетом. NOMOTHETIKA: Философия. Социология. Право. 45 (2): 271-280. DOI 10.18413/2712-746X-2020-44-2-271-280

\section{Management of project teamwork as a social technology package}

\author{
Marina A. Fedotova ${ }^{1}$, Pyotr V. Polushin ${ }^{2}$ \\ ${ }^{1}$ Moscow aviation institute (National research university)", \\ 4 Volokolamsk highway, Moscow, 125993, Russia \\ ${ }^{2}$ Academy of The state fire service of the EMERCOM of Russia \\ 4 Boris Galushkin St, Moscow, 129366, Russia \\ E-mail: fedotova-ma@yandex.ru, petr-poluchin@rambler.ru
}

\begin{abstract}
The author's interpretation of the development of the theory of social technologies based on the concept of socionavigation in the form of a Technopack approach (TP - approach) to the system management of project teamwork, based on the representation of this activity as a process in the technological network ("Technopack" - TP). Actual problems of system management of project team work, which solutions are necessary to improve the efficiency of management practice, are identified. New, additional concepts of "developing" and "optimizing" technologies have been introduced: "developing" technology, which is a technology of development, as a rule, the key," closing " technology of TP. "Developing" technology allows improving the TA, adapting it to social and technical and technological changes. "Optimizing" technology - technology that allows you to optimize the parameters
\end{abstract}


of the "basic" and "product" technologies used. The concept of an integrated system of models of the information sub-package of the Technopack "system management of project teamwork", based on "soft" calculations (MAI/MAS technologies of T. Saati), is proposed.

Keywords: social technologies, socio navigation, Technopack, MY / MAZ-technologies of T. Saati, integrated system of models as an information sub-package.

For citation: Fedotova M.A., Polushin P.V. 2020. Management of project teamwork as a social technology package. NOMOTHETIKA: Philosophy. Sociology. Law series. 45 (2): 271-280 (in Russian). DOI 10.18413/2712-746X-2020-44-2-271-280

\section{Введение}

Для исследования современных социальных явлений и процессов используются более сложные, чем классические дискретные, модели аналитического теоретизирования. Прежде всего, это модели средового анализа и прогнозирования [Переслегин, 2009; Сценарный стратегический прогноз, 2016], позволяющие более корректно представить такие процессы в неравновесных, турбулентных ситуациях («на кромке хаоса»), превалирующих сегодня. Среди существующих концепций средового анализа - описаний будущего, средового прогнозирования, различного вида форсайтов и т.д. - наиболее интересной, на взгляд авторов статьи, является концепция технопакетов С.Б. Переслегина, позволяющая связать стратегии социально-экономического развития с технологизацией, формируя структуру фазового технологического пространства [Переслегин, 2015].

Социальные технологии (СТ), естественным развитием которых является концепция технопакетов, до сих пор не являются предметом системного междисциплинарного научного исследования, их включение в управление носит, по большей части, частный, случайный характер. Существует множество различных видов и классификаций социальных технологий по различным критериям [Щербина, 2007; Тощенко, 2009; Касавин, 2010; Осипов, 2011; Юдин, 2012; Касавин, 2012, Маркова, 2012; Герасимов, Чумак, 2014; Щербина, 2014; Осипов, 2017]. Однако на сегодняшний день эта задача не получила своего практического разрешения. Существует разрыв между социальными науками и практикой принятия макросоциальных решений, несущих высокие риски. Необходима «экологическая», «мягкая», структурно сбалансированная и метрически просчитанная система социальных действий.

Для достижения этой цели нужны новые проектные технологические подходы к социальному управлению, учитывающие сложные взаимосвязи в системе социального управления и технологизации [Касавин, 2010, с. 10], а также решение следующих задач, связанных с внедрением в социальную практику концепции технопакетирования:

1. Определить особенности технопакетного подхода в системном управлении проектной командной работой.

2. Провести диагностику состояния и ключевых факторов социальных технологий, входящих в технопакет, выделить актуальные проблемы системного управления проектной командной работой с точки зрения его технологизации.

3. Расширить и развить содержание технологий, входящих в технопакет, определить пути повышения их эффективности как единой социотехнологической системы, элиминировать формальные аспекты технологизации, игнорирующие социальные ценности и этические аспекты (эта задача решается в рамках концепции соционавигации как социальной практики, основанной на социоэмпатии [Федотова, 2019] и концепции посттехногенной цивилизации [Лепский, 2019]).

4. Обосновать систему технологического моделирования управления проектной командной работой в виде иерархии моделей, основанных на «мягких» вычислениях. 


\section{Объекты и методы исследования}

Имеющийся опыт успешного системного управления проектными командами свидетельствует об отсутствии специально сформированного социального технопакета «системное управление проектной командной работой», а также о невысоком уровене компетентности участников проектных команд и, прежде всего, менеджмента команд. Упрощенная схема (критериями или полюсами классификации которой являются параметры: «системность - несистемность», «открытость - закрытость» и «функциональность структурность») эволюции представлений о развитии социальных технологий командной работы с учетом развития моделей управления командной работой [Федотова, 2018], приведена на рис. 1.

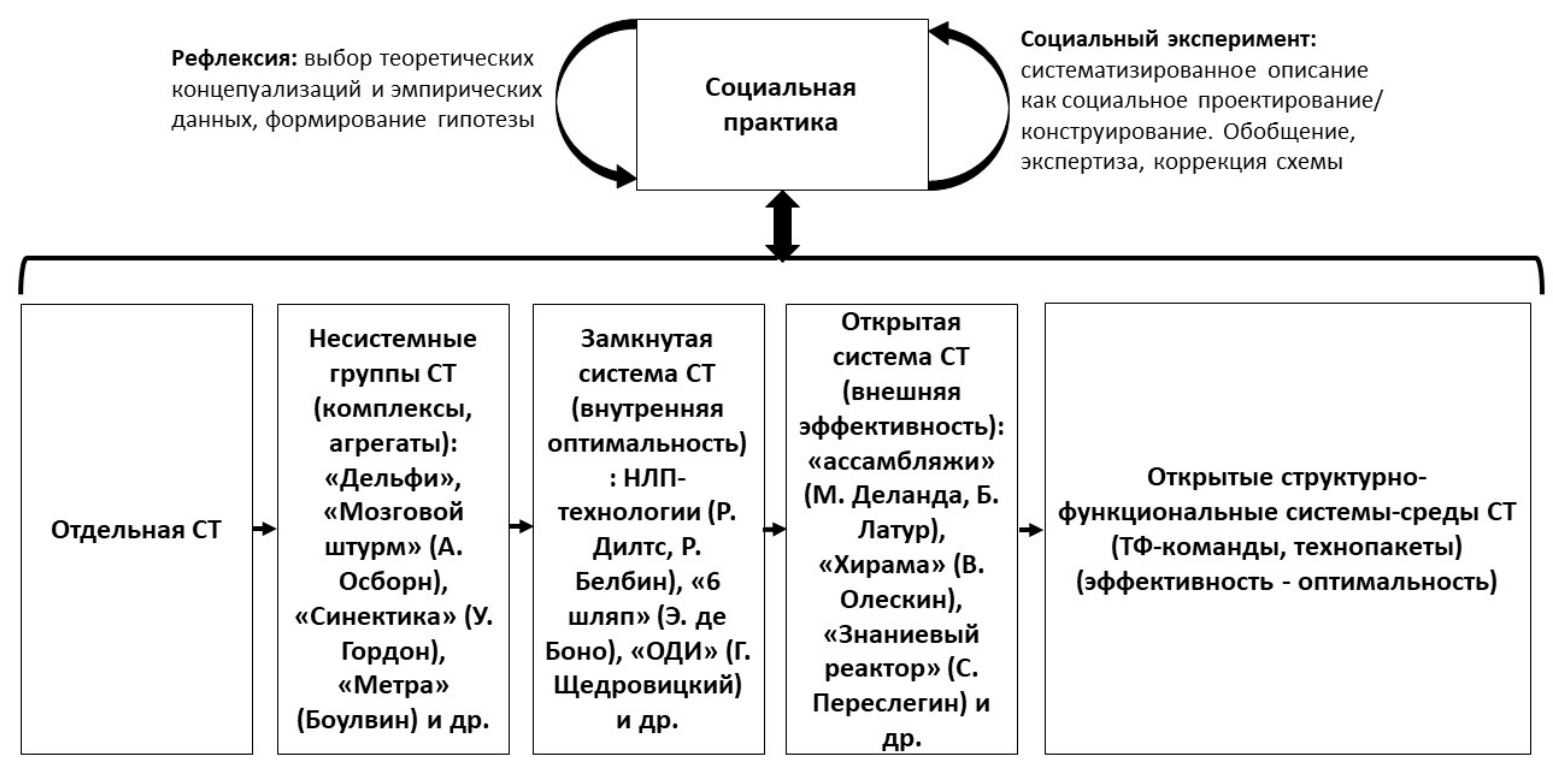

Рис. 1. Эволюция представлений о развитии социальных технологий командной работы

Fig. 1. Evolution of ideas about the development of social technologies of teamwork

Если добавить в классификацию дополнительный параметр масштабности «микромезо - макро - мега», то получим полную классификацию социальных технологий, включающую в себя как микроформы СТ [Герасимов, Чумак, 2014], так и мегаформы СТ «цивилизация как мегатехнология» [Осипов, 2017]. В первой работе социальные технологии, по сути дела, аналогичны технологиям бизнес-проектирования в социальной сфере. Технологический пакет (ТП) - генетически и структурно-функционально связанная совокупность различных технологий, системного характера, реализующая одну из социальнозначимых потребностей [Переслегин, 2015]:

1. «Базовая» онтологема - «теоретическая идея или идеологема, метафора/миф, лежащая в основе представлений о пакете» - «один в поле не воин», а также научные дисциплины, участвующие в формировании ТП (социология управления, социология организации, социология микрогрупп, социальная психология, менеджмент и др.).

2. «Базовая» технология (субпакет) - технология, делающая пакет «физически» возможным, развитие которой привело к формированию пакета. В нашем случае, базовой технологией ТП является технология формирования (диагностики) команд.

3. «Продуктовые» технологии (субпакеты) - физические, гуманитарные (управляющие) технологии, обеспечивающие производство, обмен и реализацию или утилизацию конечных товаров услуг, социоформ проектов, в том числе самих команд как «продуктов» проектирования и конструирования. В нашем случае, продуктовыми технологиями явля- 
ются технологии управленческого проектирования как классические, так и неклассические (Agile-технологии) технологии, а также технологии системной аналитики [Шевырев, Михеев, Шаламова, Федотова, 2016].

«Замыкающая» технология (субпакет) - системно-организующая технология, связывающая набор отдельных технологий. В нашем случае, «замыкающей» технологией является технология (субпакет) управления образовательно-карьерной и деловой (аутсорсинг) траекторией команд. Наличие «биржи» команд приводит к целесообразной, экономически выгодной трансформации социальной среды, позволяющей эффективно развивать технопакет (в этом случае решение является собственной функцией среды).

«Закрывающие» технологии (субпакеты) - это технологические пакеты, позволяющие удовлетворять существующие потребности на более качественном уровне, чем имеющиеся технопакеты (с меньшими затратами ресурсов и негативными последствиями, свойственными традиционным технопакетам). В нашем случае, это технология использования командной работы на основе искусственного интеллекта (AI) (хотя о меньших негативных последствиях говорить явно преждевременно, нужны дополнительные серьезные исследования в этой области).

Авторами вводятся дополнительные типы технологий: «оптимизирующие» и «развивающие».

«Оптимизирующие» технологии (субпакеты) позволяют рационализировать (оптимизировать) параметры используемых «базовой» и «продуктовых» технологий. В нашем случае, «оптимизирующими» технологиями являются инновационные технологии модерации и фасилитации командной работы («хирама», «знаниевый реактор» и др.), а также новые, «гибкие» фреймворки управления проектами (SCRUM, SMC).

«Развивающие» технологии (субпакеты) - технологии развития, как правило, ключевой, «замыкающей» технологии или парадоксальным образом (что характерно для системно - креативного мышления) «закрывающей» технологии ТП. «Развивающая» технология позволяет совершенствовать ТП, адаптируя его к культурно-социальным и техниктехнологическим изменениям в обществе. В случае совместного использования человеческих ресурсов (HR) и искусственного интеллекта (AI) «закрывающая» технология достраивается до «развивающей» (дополненная реальность). В нашем случае, это технология развития человеческих ресурсов (H-> $\left.\mathrm{H}^{\prime}\right) \mathrm{R}$ (возможно в измененных состояниях сознания), прежде всего, развития когнитивных и коммуникативных метакомпетенций команды и ее единого креативного поля (ЕКП) [Михеев, Федотова, Шевырев, 2013] и их синтеза с искусственным интеллектом (AI):((H->H') \&AI)R-технологии. Такой переход, как правило, временный (в виде рекурсивных петель с повышающейся с каждым циклом интенсивностью, «плотностью» когнитивной деятельности), осуществляется на базе измененных состояний сознания (ИСС) [Tart, 1986; Гроф, 1994; Уилбер, 2002] отдельных участников команд и команд в целом. Как известно, исследования ИСС показали, что некоторые виды знания состояние-специфичны (Tart, 1986). Если вы не находитесь в определённом состоянии сознания, то вам будут недоступны некоторые знания специфического характера. Собственно говоря, единое креативное поле команды возникает именно как ИСС, например, аналогично феномену массовой паники [Михеев, Федотова, Шевырев, 2013]. Большая часть физических и управляющих технологий развивается по законам, аналогичным законам биологической эволюции (Г.С. Альтшуллер, Г.Я. Буш). Однако есть исключения («черные лебеди» Н. Талеба), появление таких технологий ведет к кардинальным социально-экономическим и политическим изменениям. Предсказать подобные технологические «скачки», не имеющие технологических и эволюционных предшественников, практически невозможно, такие, совершенно непредсказуемые, технологии были названы «Эдем-технологиями» (спонтанными) (А. Столяров), например, «колесо», «застежкамолния», «канцелярская скрепка» (Переслегин, 2015). 
В технопакет включаются также базовые инфраструктура и институты. Базовая инфраструктура - ключевая инфраструктура для развития социальной системы в целом. B нашем случае это коммуникационная среда организации, имеющей корректную HRстратегию. Любые жизнеспособные HR-решения должны (прежде всего, логически и эмоционально) соответствовать этой инфраструктуре.

Базовыми институтами в нашем случае могут быть любые оргформы командной работы с надлежащим правовым оформлением (см. рис. 1).

Таким образом, технологии, входящие в технопакет, во-первых, взаимозависимы и развиваются совместно; во-вторых, модифицируют друг друга в процессе развития. Структура предлагаемого технопакета с конкретным функциональным наполнением приведена на рис. 2.

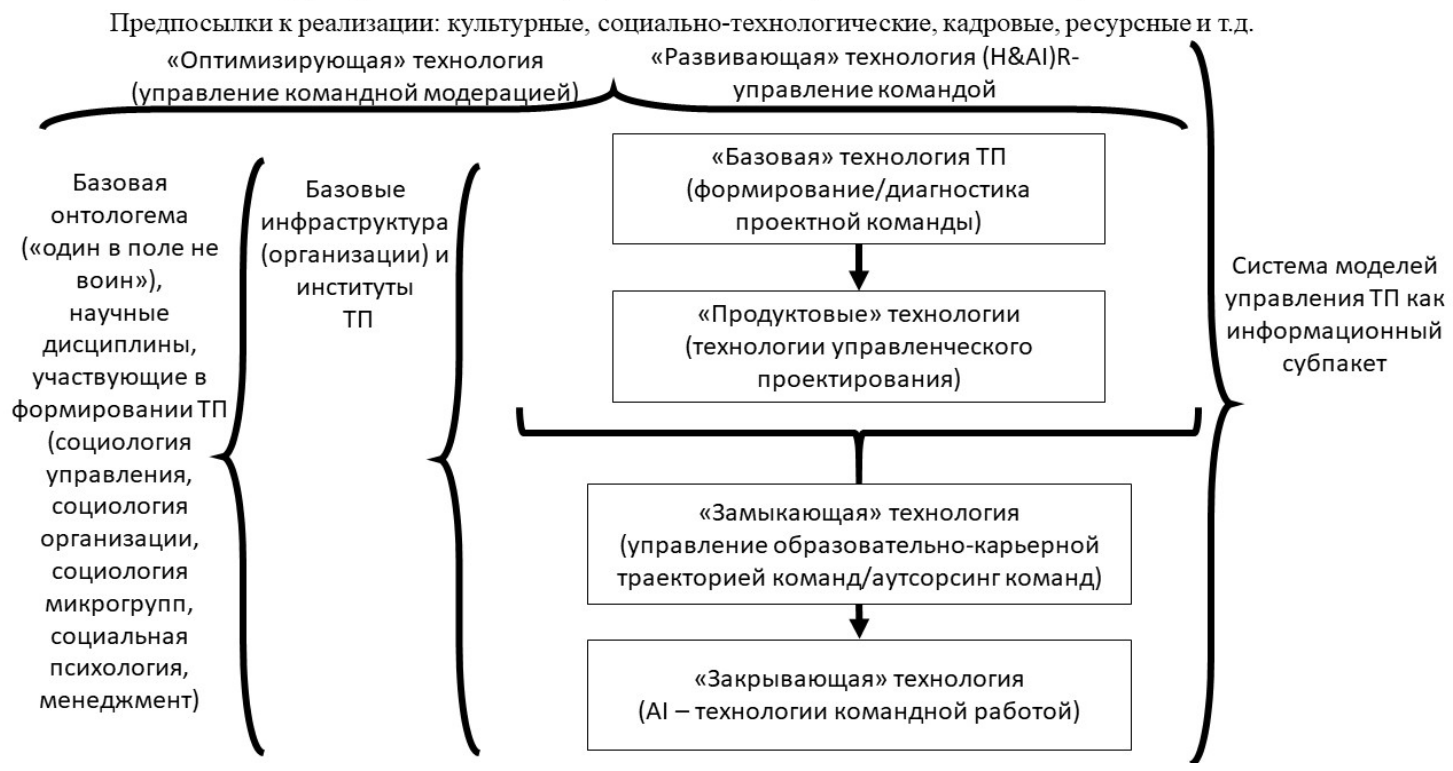

Рис. 2. Структура технопакета

Fig. 2. Technopack Structure

Избыточная технологичность технопакетного подхода нивелируется за счет использования методов соционавигации [Шевырёв, Михеев, Шаламова, Федотова, 2016]. В данной концепции российских авторов эта цель достигается путём формирования и управления единым креативным полем (ЕКП) участников команд и команды в целом на основе социоэмпатии как ключевого фактора успешности коммуникаций, а также использованием специальных технологий и моделей мышления в системной аналитике [Шевырёв, Михеев, Шаламова, Федотова, 2013, 2016]. Осуществляется сдвиг к постнеклассическому типу рациональности (переход от целевого и средового планирования к атрибутивному проектированию - наличие атрибутивных свойств системы страхует от незапланированных рисков). От форсайта соционавигация отличается своей направленностью на текущую ситуацию, а от социосерфинга - возможностью (и способностью) «умного» достраивания социальной реальности, используя структурные гипотезы самого высокого уровня абстракции (аналогично, например, принципам суперпозиции, неопределенности и дополнительности в квантовой физике). При этом соционавигация максимально приспособлена к неожиданно возникающим новым возможностям, используя принцип «via negativa» (путь отрицания или принцип хрупкости хорошего: о том, что неверно, мы можем судить с большей уверенностью, чем о том, что верно, используя технологию субтрактивного прогнозирования и «эффект Линди» Н. Талеба) [Талеб, 2020]. Смысл социо- 
навигации - не попадать в зоны глубокого равновесия (гомеостаза) и хаоса. Необходимо использовать энергию разрушения социальной системы (палингенез А. Тойнби) [Тойнби, 2002] в целях достижения нового динамического равновесия.

Ключевой задачей социального управления, с точки зрения концепций соционавигации и технопакетирования, является поиск (формирование) «замыкающих» и «закрывающих» технологий (желательно, для избегания катастрофических социальных противоречий, с трансформацией (эволюцией) последних в «развивающие» технологии). Для решения этой задачи предлагается использовать методы «мягких» вычислений и технологии проектного управления. Как известно, любой командный проект является сложной системой различных видов деятельности, осуществляемой с помощью управленческого проектирования (либо классического РМBoK, ТОС и др., либо неклассического (Agile) SCRUM, SMC и др., последние более предпочтительны в условиях неравновесного VUCA-мира и замены традиционных концепций менеджмента на постнеклассические инновационно-креативные). Ровно в силу этих же условий, и, прежде всего, невозможности четкого (однозначного) структурирования решаемых задач и проблем малоэффективны чисто аналитические (математические) методы, наиболее часто используемые статистические. Выходом из сложившейся ситуации может быть использование мультиэкспертных методов, основанных на «мягких» вычислениях (нечёткая логика) [Синюк, Шевырев, 2003; Саати, 2008]. В технопакетировании командной работы предлагается использовать МАИ/МАС - технологии Т. Саати в схеме адаптивного планирования (управления, стратегирования) проблемными ситуациями (ПС) [Синюк, Шевырев, 2003]. Схема такого стратегирования приведена на рис. 3.

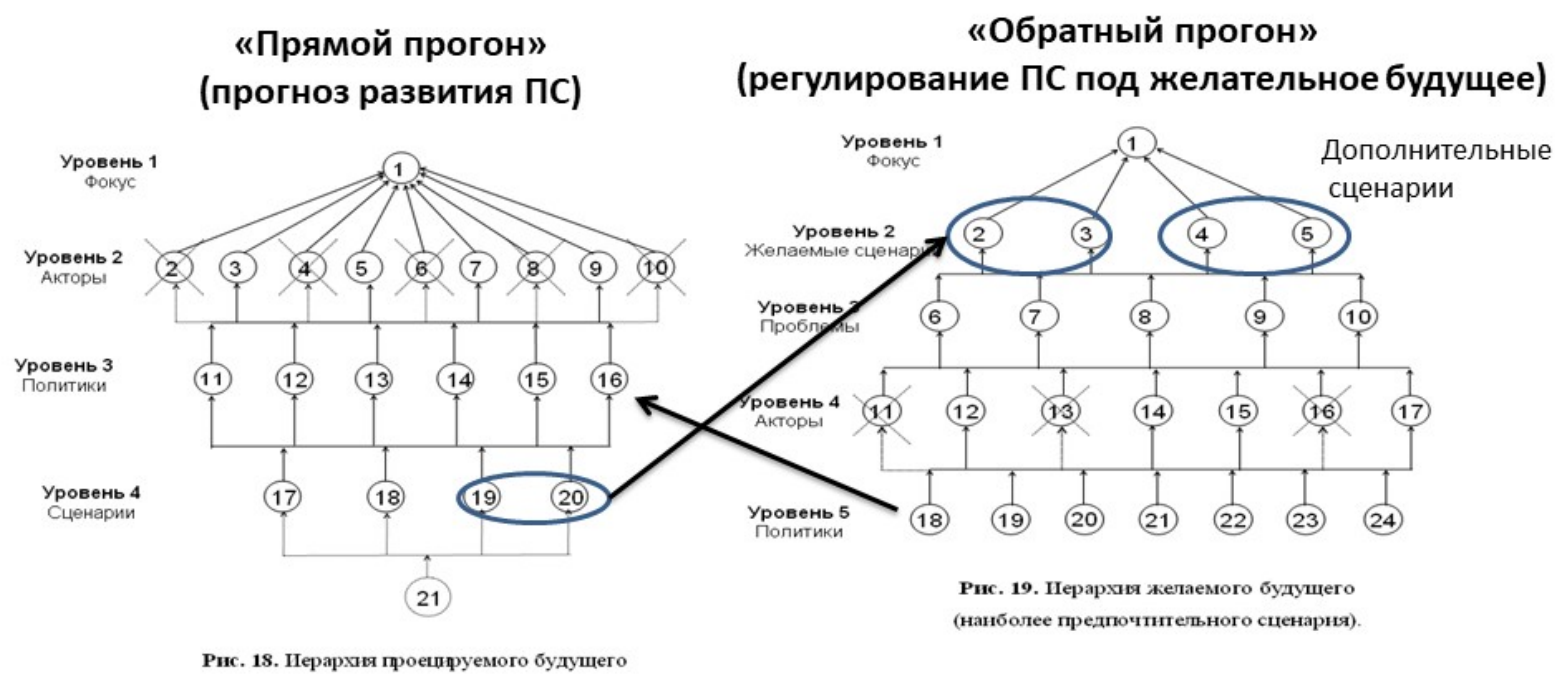

Рис. 3. Управление (стратегирование) проблемными ситуациями Fig. 3. Management (Strategizing) problem situations

Стратегическое адаптивное (резонансное) планирование (стратегирование) - это непрерывное «мягкое», в режиме «бриколажа», управление, о котором говорилось выше. Подробное описание процесса приведено в работе Синюка, Шевырева [2003].

В отличие от МАИ, метод анализа сетей (МАС) учитывает возможные обратные связи в иерархии, что в некоторых случаях принципиально необходимо (рис. 4). 


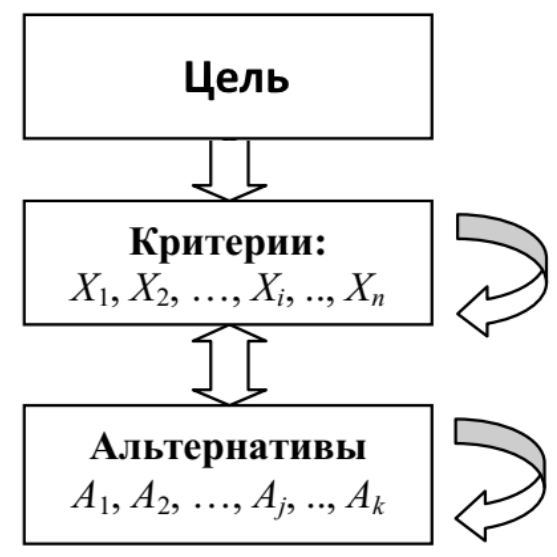

Рис. 4. Схема МАС-технологии

Fig. 4. MAC technology Diagram

Однако этот метод ведет к нежелательному значительному росту размерности суперматрицы «W». В этом случае используется специальная BOCR-модификация МAИ «выгоды - затраты - возможности - риски».

Управляющим субпакетом (гуманитарной технологией) ТП «Системное управление командной работой» является информационно-аналитический субпакет «Интегральная система моделей управления ТП», предназначенный для системного управления технопакетом в целом. Упрощенное представление интегральной системы моделей управления ТП в виде информационно-аналитического субпакета (гуманитарной (управляющей) технологии) приведено на рис. 5, где opt $\mathrm{A}_{\mathrm{j}}$ - оптимальная j-я характеристика на i-ом этапе процесса системного управления командной работой, используемая как входной параметр на смежном (i+1)-ом этапе).

Уровни управления технопакетом
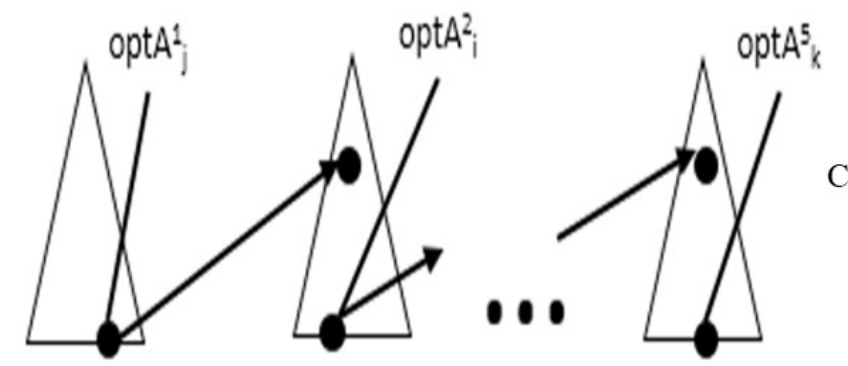

Система МАИ/МАС - моделей Т. Саати

Этапы процесса системного управления командной работой (технологиями субпакета) $\quad \mathrm{t}$

Рис. 5. Интегральная система моделей ТП «системное управление проектной командой» Fig. 5. Integrated system of TP models system management of the project team

Синтез и общая адаптация к средовым изменениям различных уровней (технологий ТП) иерархии (см. аналогично схеме рис. 3) в предлагаемой интегральной системе моделей осуществляется путем пересчета характеристик, полученных на одном этапе процесса управления субпакетами технопакета, в параметры моделей, используемых на другом (смежном) этапе (см. рис. 5), например, характеристики команд («базовая» технология (субпакет)) влияют на выбор методов управленческого проектирования («продуктовая» технология), которые, в свою очередь, влияют на эффективность командной работы и т.д. 
По завершении одного цикла управления пакетом, процесс повторяется по схеме адаптации (см. рис. 3) до получения необходимого результата (достижения желаемого будущего).

\section{Заключение}

Во-первых, неопределенность и нестабильность VUCA мира создают серьезные вызовы управлению бизнес-проектами в целом и управлению командами как инструментом управленческого проектирования в частности.

Во-вторых, управление сложными социальными системами недостаточно эффективно из-за неадекватности состояния объектов управления и сложности управляющих систем. В этом случае необходима иерархическая система моделей (технологий (субпакетов) ТП) обеспечения системного управления командами для различных этапов развития проблемной ситуации.

В-третьих, представляется, что наиболее перспективными технологиями системного стратегирования процессами проектной командной работы являются иерархические системы моделирования [Шевырев, Михеев, Шаламова, Федотова, 2016].

В-четвертых, процесс технопакетирования команд значительно повышает эффективность их использования в проектном управлении за счет выделения критических, на данном этапе развития проблемной ситуации, технологий (субпакетов), инициируя их активный поиск (конструирование) и использование.

В-пятых, введение авторами новых понятий в процесс технопакетирования - «оптимизирующих» и «развивающих» технологий позволяет значительно повысить эффективность процесса стратегирования за счет повышения адекватности управляющей системы и объекта управления (закон необходимого разнообразия У.Р. Эшби).

\section{Список литературы}

1. Герасимов Б.Н., Чумак В.Г. 2014. Социальные технологии в управлении. Самара, СамНЦ РАН, 396 с.

2. Гроф С. 1994. Области человеческого бессознательного. М., Институт трансперсональной психологии, $280 \mathrm{c}$.

3. Касавин И.Т. 2010. Социальные технологии и научное знание. Эпистемология и философия науки, (4): 5-15.

4. Касавин И.Т. 2012. Социальные технологии. теоретические концептуализации и примеры. Общественные науки и современность, (6): 100-111.

5. Лепский В.Е. 2019. Системные основания для перехода от техногенной цивилизации к социогуманитарной цивилизации. Проблемы цивилизационного развития, (1): 33-48.

6. Маркова Л.А. 2012. Технологии в социальных и технических системах: социальный и гуманитарный анализ. Эпистемология и философия. Наука, (1): 64-72.

7. Михеев В.А., Федотова М.А., Шевырёв А.В. 2013. Рабочая команда как сетевая структура, индуцирующая единое креативное поле. Экономические стратегии, (5): 64-67.

8. Осипов Н.Е. 2017. Еще раз о социальных технологиях. Философия и общество, 1(82): $5-28$.

9. Осипов Н.Е. 2011. Содержание и методологическая роль категории «социальная технология» в осмыслении целостности общества. Вопросы философии, (6): 16-21.

10. Переслегин С.Б. 2009. Новые карты будущего, или анти-рэнд. М., АСТ: АСТ МОСКВА, СПб.: Terra Fantastica, $701 \mathrm{c.}$

11. Переслегин С.Б. 2015. Дикие карты будущего, форс мажор для человечества. М., Алгоритм, $407 \mathrm{c}$.

12. Саати Т.Л. 2008. Принятие решений при зависимостях и обратных связях: аналитические сети. М., Издательство ЛКИ, 356 с. ИНЭС РАН.

13. Сценарный стратегический прогноз. Пермский край, Россия и мир - 2030. 2016. М.,

14. Талеб Н.Н. 2020. Антихрупкость. Как извлечь выгоду из хаоса. М., КоЛибри, 764 с. 
15. Тойнби А.Дж. 2001. Постижение истории: Сборник. Перевод с англ. Е.Д. Жаркова, М., Рольф, 640 с.

16. Тощенко Ж.Т. 2013. Тезаурус социологии. М., ООО «Юнити-Дана», 481 с.

17. Уилбер К. 2002. Око духа: интегральное видение для слегка свихнувшегося мира. М., «Изд-во АСТ, $476 \mathrm{c.}$

18. Федотова М.А. 2018. Системное управление командной работой: эволюция представлений и перспектива развития. Научный результат. Социология и управление, 4 (4):137-151.

19. Федотова М.А. 2019. Постнеклассическое стратегирование проблемных ситуаций в концепции соционавигации: переход от целевого управления к атрибутивному конструированию. Экономические стратегии, 21 (8 (166)): 94-101.

20. Шевырёв А.В., Михеев В.А., Шаламова Н.Г., Федотова М.А. 2016. Системная аналитика в управлении. Введение в научно-исследовательскую программу (под общей редакцией Шевырёва А.В.). Белгород, ЛитКараВан, 384 с.

21. Щербина В.В. 2014. Социальные технологии: история появления термина, трансформация содержания, современное состояние. Социологические исследования, (7):113-124.

22. Щербина В.В. 2007. Социолого-диагностические технологии в управлении: теоретикометодологические аспекты развития и применения. Социологические исследования, (3): 30-42.

23. Юдин Б.Г. 2012. Социальные технологии, их производство и потребление. Эпистемология и философия науки, (1): 55-64.

24. Tart C.T. 1986. Consciousness, altered states, and worlds of experience. The Journal of Transpersonal Psychology, 18 (2): 159-170.

\section{References}

1. Gerasimov B.N., CHumak V.G. 2014. Social'nye tekhnologii v upravlenii [Social technologies in the management of]. Samara, SamNC RAN, 396 p.

2. Grof S. 1994. Oblasti chelovecheskogo bessoznatel'nogo [Areas of the human unconscious]. M., Institut transpersonal'noj psihologii, $280 \mathrm{p}$.

3. Kasavin I.T. 2010. Social'nye tekhnologii i nauchnoe znanie [Social technologies and scientific knowledge]. Epistemologiya i filosofiya nauki, (4): 5-15.

4. Kasavin I.T. 2012. Social'nye tekhnologii. teoreticheskie konceptualizacii i primery [Social technology. theoretical conceptualizations and examples]. Obshchestvennye nauki i sovremennost', (6): $100-111$.

5. Lepskij V.E. 2019. Sistemnye osnovaniya dlya perekhoda ot tekhnogennoj civilizacii k sociogumanitarnoj civilizacii [System foundations for the transition from industrial civilization to civilization Humanities]. Problemy civilizacionnogo razvitiya, (1): 33-48.

6. Markova L.A. 2012. Tekhnologii v social'nyh i tekhnicheskih sistemah: social'nyj i gumanitarnyj analiz [Technologies in social and technical systems: social and humanitarian analysis]. Epistemologiya i filosofiya. Nauka, (1): 64-72.

7. Miheev V.A., Fedotova M.A., SHevyryov A.V. 2013. Rabochaya komanda kak setevaya struktura, induciruyushchaya edinoe kreativnoe pole [A work team as a network structure that induces a single creative field]. Ekonomicheskie strategii, (5): 64-67.

8. Osipov N.E. 2017. Eshche raz o social'nyh tekhnologiyah [Once again about social technologies]. Filosofiya i obshchestvo, 1(82): 5-28.

9. Osipov N.E. 2011. Soderzhanie i metodologicheskaya rol' kategorii «social'naya tekhnologiya» v osmyslenii celostnosti obshchestva [Content and methodological role of the category "social technology" in understanding the integrity of society]. Voprosy filosofii, (6): 16-21.

10. Pereslegin S.B. 2009. Novye karty budushchego, ili anti-rend [New maps of the future, or anti-Rand]. M., ACT: ACT MOSKVA, SPb.: Terra Fantastica, 701 p.

11. Pereslegin S.B. 2015. Dikie karty budushchego, fors mazhor dlya chelovechestva [Wild cards of the future, force majeure for humanity]. M., Algoritm, $407 \mathrm{p}$.

12. Saati T.L. 2008. Prinyatie reshenij pri zavisimostyah i obratnyh svyazyah: analiticheskie seti [Decision making with dependencies and feedbacks: analytical networks]. M., Izdatel'stvo LKI, 356 p.

13. Scenarnyj strategicheskij prognoz [Scenario-based strategic forecast]. Permskij kraj, Rossiya i mir - 2030. 2016. M., INES RAN. 
14. Taleb N.N. 2020. Antihrupkost'. Kak izvlech' vygodu iz haosa [Antifragility. How to capitalize on chaos]. M., KoLibri, 764 p.

15. Tojnbi A. Dzh. 2001. Postizhenie istorii: Sbornik [A study of history: a Collection of] perevod s angl. E.D. ZHarkova, M., Rol'f, 640 p.

16. Toshchenko ZH.T. 2013. Tezaurus sociologii [Thesaurus of sociology]. M., OOO «YUnitiDana», $481 \mathrm{p}$.

17. Uilber K. 2002. Oko duha: integral'noe videnie dlya slegka svihnuvshegosya mira [Eye of spirit: integral vision for a slightly deranged world]. M., «Izd-vo AST», 476 p.

18. Fedotova M.A. 2018. Sistemnoe upravlenie komandnoj rabotoj: evolyuciya predstavlenij i perspektiva razvitiya [System management of team work: the evolution of ideas and prospects for development]. Nauchnyj rezul'tat. Sociologiya i upravlenie, 4 (4):137-151.

19. Fedotova M.A. 2019. Postneklassicheskoe strategirovanie problemnyh situacij v koncepcii socionavigacii: perekhod ot celevogo upravleniya $\mathrm{k}$ atributivnomu konstruirovaniyu [Postnonclassical strategizing problematic situations in the concept of sociological: the transition from task management to attribute design]. Ekonomicheskie strategii, 21 (8 (166)): 94-101.

20. Shevyryov A.V., Miheev V.A., SHalamova N.G., Fedotova M.A. 2016. Sistemnaya analitika $\mathrm{v}$ upravlenii. Vvedenie $\mathrm{v}$ nauchno-issledovatel'skuyu programmu [System Analytics in management. Introduction to the research program (under the General editorship of A.V. Shevyrev)]. Belgorod, LitKaraVan, $384 \mathrm{p}$.

21. Shcherbina V.V. 2014. Social'nye tekhnologii: istoriya poyavleniya termina, transformaciya soderzhaniya, sovremennoe sostoyanie [Social technologies: the history of the term, content transformation, current state]. Sociologicheskie issledovaniya, (7):113-124.

22. Shcherbina V.V. 2007. Sociologo-diagnosticheskie tekhnologii v upravlenii: teoretikometodologicheskie aspekty razvitiya i primeneniya [Socio-diagnostic technologies in management: theoretical and methodological aspects of development and application]. Sociologicheskie issledovaniya, (3): 30-42.

23. Yudin B.G. 2012. Social'nye tekhnologii, ih proizvodstvo i potreblenie [Social technologies, their production and consumption]. Epistemologiya i filosofiya nauki, (1): 55-64.

24. Tart C.T. 1986. Consciousness, altered states, and worlds of experience. The Journal of Transpersonal Psychology, 18 (2): 159-170.

\section{ИНФОРМАЦИЯ ОБ АВТОРАХ}

Федотова Марина Александровна, к.э.н., доцент кафедры «Управление персоналом» Московского авиационного института (национального исследовательского университета), г. Москва, Россия

Полушин Петр Владимирович, заместитель начальника учебного отдела учебнометодического центра Академии Государственной противопожарной службы МЧС России, г. Москва, Россия

\section{INFORMATION ABOUT THE AUTHORS}

Marina A. Fedotova, Ph. D. in Economics, associate Professor of the Department of personnel Management at the Moscow aviation Institute (national research University), Moscow, Russia

Pyotr V. Polushkin, Deputy head of the training Department of the training and methodological center of the Academy of The state fire service of the EMERCOM of Russia, Moscow, Russia 